\title{
Impact assessment of a severe dust storm on atmospheric aerosols over an urban site in India
}

\author{
Kanika Taneja $^{1, *}$, Shamshad Ahmad ${ }^{1}$, Kafeel Ahmad ${ }^{1}$ and S. D. Attri ${ }^{2}$ \\ ${ }^{1}$ Jamia Millia Islamia, New Delhi 110 025, India \\ ${ }^{2}$ India Meteorological Department, New Delhi 110003 , India
}

\begin{abstract}
An intense dust storm occurred over the northwestern part of India between 28 and 31 May 2014, that drastically reduced air quality and visibility over the region. This study evaluates the impact of dust storm on aerosol characteristics over the mega city of Delhi. As the storm reached Delhi on 30 May 2014, the $\mathbf{P M}_{10}$ concentration soared to an unusually high value of more than $933 \mu \mathrm{g} \mathrm{m}^{-3}$. The aerosol optical properties such as aerosol optical depth (AOD), Ångström exponent (AE), single scattering albedo (SSA), and asymmetry parameter were measured using the groundbased sky radiometer installed at India Meteorological Department (IMD), New Delhi. During the dust event, higher AOD was recorded at $500 \mathrm{~nm}(1.456 \pm 0.158)$, while AE dropped to 0.287. Large variation in SSA indicated the optical state of dust to be more absorbing in nature. The water vapour content in the atmosphere was also analysed from measurements taken at the $940 \mathrm{~nm}$ channel of the instrument. During the study period, radiative forcing at the surface, atmosphere and top of the atmosphere ranged from -31 to 82,15 to 92 and 2 to $10 \mathrm{Wm}^{-2}$ respectively. On the day of dust storm, large reduction in aerosol radiative forcing was observed at the surface level that caused significant cooling.
\end{abstract}

Keywords: Atmospheric aerosol, dust storm, sky radiometer, radiative forcing, urban site.

DUST storms are meteorological hazards common in the northwestern part of India adjacent to the Thar Desert, arising from strong wind flow which can remove large amounts of dust from the dry surface. They bring down the temperature, lower the humidity and reduce visibility over the target region. Dust aerosols have a huge impact on the global climate system, as they are capable of enhancing the radiative properties of the atmosphere ${ }^{1-4}$. According to Lau et al. $^{5}$ dust is considered as absorbing aerosols that cause heating in the lower atmosphere, and can further lead to enhanced convection and high rainfall in summer over North India. Thus radiative heating/cooling effect by dust can alter the atmospheric

*For correspondence. (e-mail: kanikatnj@gmail.com) dynamics and thermodynamics. Apart from the heating/ cooling effect or direct effect, desert dust impacts the Earth's climate by interacting with liquid or ice clouds (indirect effect) acting as cloud condensation nuclei that can alter the precipitation process ${ }^{6,7}$. Unlike greenhouse gases, dust aerosols have a shorter lifetime of a few days to weeks; they yet can be transported by strong winds over long distances. The journey of soil dust particles from the surface to the atmosphere is a several-steps process in which they get disintegrated from larger (100$200 \mu \mathrm{m}$ diameter $)$ to smaller $(\sim 50 \mu \mathrm{m})$ sized particles before being transported ${ }^{8}$. Once dust particles enter the human respiratory system, they can get deposited in the gas-exchange chamber of the lungs and pose adverse health impacts. Thus, dust is an intriguing part of the climate as well as human health.

Desert dust and anthropogenic emissions are the major sources of high aerosol concentration in Asia ${ }^{9}$, which is considered to be the heaviest aerosol laden region in the world. Various studies have shown higher aerosol loading with high aerosol optical depth (AOD) values over northern India during the pre-monsoon season due to dust activities ${ }^{10-13}$. Usually the origin of dust storms over the northern part of India is from three main sources, namely Oman, the Great Indian Desert (Thar Desert) and Southwest Asia ${ }^{11}$. According to Jin et al. ${ }^{14}$ the Middle East dust enhances the southwesterly monsoon flow over southern and northern India. While several studies have been conducted on dust storms originating from Sahara and Gobi Desert $^{15,16}$, only a few have covered the comprehensive impact of dust from the Great Indian Desert in West India and East Pakistan, and Margo Desert in adjoining Afghanistan ${ }^{17}$. Usually during the early summer months (between April and May), dust aerosols are transported from neighbouring deserts over northern India. This has a considerable effect on ambient air quality and climate variability of the Indo-Gangetic Plains (IGP). As the wind circulates dust over the IGP, it gets coated with heavy metals during transport. Mixing with anthropogenic pollutants results in alteration of chemical composition of dust particles. Hence dust shows variable scattering and absorbing properties. According to Moorthy et al. ${ }^{18}$ dust over the Thar Desert is more absorbent in nature than the 
Saharan dust. Although some studies show that dust mostly scatters light ${ }^{10}$, iron oxide and silica present in the dust particles are responsible for absorption.

The conjugation of desert dust with anthropogenic emissions makes the study of dust aerosols more complicated and challenging. The present study is based on the impact of such dust activity on the optical properties of aerosols in the urban capital of India. Delhi is situated in the heart of the IGP and is considered as the most polluted mega city in Asia. The atmosphere in Delhi is heavily subjected to vehicular and industrial emissions, desert dust and massive construction activities ${ }^{10,19}$. The intensity of dust storms in Delhi is high during April-June $e^{7,11,20}$. An unusual dust plume that was generated as a cyclonic circulation from a western disturbance over North Pakistan and adjoining Afghanistan, affected the northwest region of India between 27 and 31 May 2014 and encountered Delhi on 30 May 2014 by 17:00 h. Very high wind speed was recorded $(>121 \mathrm{kmph})$ during this event. The temperature dropped from $42^{\circ} \mathrm{C}$ to $26^{\circ} \mathrm{C}$, and visibility reduced to $500 \mathrm{~m}$. The dust storm soon turned into a heavy rainstorm, with high winds raging through the city.

Satellite remote sensing of dust activities has been attempted in previous studies to analyse the spatio-temporal distribution and trends using Moderate-resolution Imaging Spectroradiometer (MODIS) and Multi-angle Imaging Spectroradiometer (MISR) datasets ${ }^{21}$. In the present study, optical properties of aerosols like AOD, single scattering albedo (SSA), Ångström exponent (AE) and aerosol size distribution were analysed for the dust period using a multi-wavelength instrument, viz. sky radiometer. The $940 \mathrm{~nm}$ channel of the sky radiometer has not been extensively used to compute precipitable water vapour (PWV) over India. In the present study, we make use of this wavelength channel to analyse the impact of dust storm on columnar water vapour. The aerosol optical properties retrieved from sky radiometer observations were further utilized to analyse the aerosol radiative forcing (ARF) for the study location.

\section{Data and methodology}

The aerosol optical properties were derived from PREDE sky radiometer (POM-02) data. The sky radiometer observes simultaneously direct and solar aureole radiance at various scattering angles from the Sun, which enables estimation of aerosol optical parameters such as AOD, AE, SSA, phase function, asymmetry parameter (ASY) and columnar size distribution of aerosols ${ }^{13}$. The measurements are made at 11 spectral channels $(315,340$, $380,400,500,670,870,940,1020,1600$ and $2200 \mathrm{~nm})$ at every $10 \mathrm{~min}$. The measured sky radiometer data have been analysed using SKYRAD.PACK software (version 4.2) for deriving optical properties of aerosols ${ }^{22}$. The data retrieved at $940 \mathrm{~nm}$ channel from PREDE sky radio- meters in India have not been utilized in measuring columnar water vapour before. In this study, the SUNRAD.pack algorithm has been used to measure this important atmospheric variable and study the impact of dust storm on the same ${ }^{23}$. While estimating calibration constant from the Langley method for urban areas, approximately $10 \%$ error was deduced by Shaw ${ }^{24}$. Therefore, an improved Langley method of calibration has been used here on the basis of both direct and diffuse radiation data $^{22,25}$. The measured spectral AOD, SSA and ASY were further used to calculate ARF. The net flux was computed in the short-wavelength range of $0.3-4.0 \mu \mathrm{m}$, with and without aerosols at the surface and top of the atmosphere (TOA) using SBDART model.

The aerosol measurements were taken for a period of one week, from 27 May to 2 June 2014. Also, 30 May was the day of intense dust storm in Delhi. However, the impact of dust event almost vanished on the following day (31 May). Therefore, non-dust days during this study were considered to be three days before and after the dust event in Delhi. The night-time data were not available as the instrument operates only in the presence of sunlight. Also, the thick dust clouds obscured the Sun during the dust storm and hence the sky radiometer data could not be retrieved during that particular time over Delhi.

\section{Results and discussion}

\section{Origin and circulation of the dust storm}

The genesis and path of the dust storm were analysed by considering 72-h back trajectories from the starting location of Delhi $\left(28.59^{\circ} \mathrm{N}, 77.22^{\circ} \mathrm{E}\right)$ using the Hybrid Single Particle Lagrangian Integrated Trajectory (HYSPLIT) model for 30 May 2014. The back trajectories were computed over the study location at three different altitudes (500, 1000 and $3000 \mathrm{~m}$ ) above ground level and were superimposed on the dust images taken from MODIS on-board the Terra and Aqua satellites (Figure 1). The thick dust mass that originated from the Arabian Peninsula on 27 May was transported through the Gulf of Oman and reached the southwestern part of Pakistan on 28 May. The air mass trajectory then curved towards northwest India on 29 May picking loose dust from the Thar Desert before reaching Delhi on 30 May (dust-storm day). Another plume that swirled at a lower altitude over the India-Pakistan border carried dust from the Thar Desert on 29 May. The strong advection of air mass was due to a western disturbance as an upper air cyclonic circulation that extended up to $3000 \mathrm{~m}$ amsl over North Pakistan and Afghanistan. This is further substantiated with the wind patterns at $925 \mathrm{hPa}$ derived from NCEP/NCAR reanalysis from 27 May to 1 June 2014 (Figure 2). Strong circulation of wind approached northwestern India over $65^{\circ} \mathrm{E}$ and $25^{\circ} \mathrm{N}$ from the Arabian Sea on 29 May. This was 


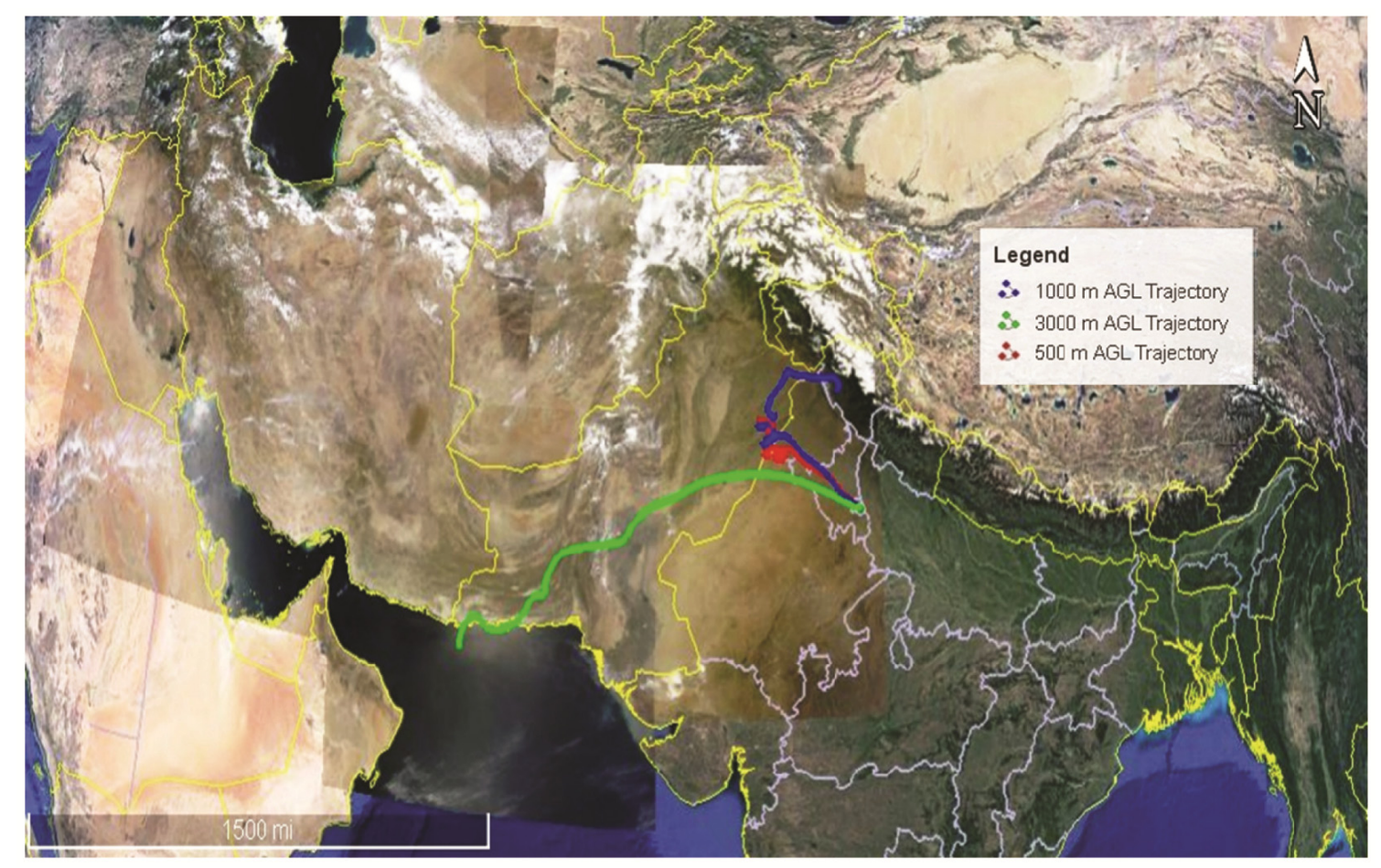

Figure 1. Dust storm observed from natural colour image captured by MODIS on-board Terra and Aqua satellites along with HYSPLIT-derived 72-h backward trajectories for Delhi on 30 May 2014.

accompanied with a strong western disturbance from northern Pakistan that induced a trough over the northwest plains of India on 30 May. Figure 2 illustrates an elongated plume on 30 May, approaching from the Arabian Sea towards the western coast of India, engulfing the northwestern plains and reducing visibility to less than $500 \mathrm{~m}$. In addition, the unusually high temperature and high moisture-laden southwesterly winds caused intense dust storm followed by heavy rainfall at 1730 LST on 30 May 2014. However, after the squall, movement of dustladen winds subsided from 31 May onwards.

\section{Impact of the dust storm on particulate matter}

Figure $3 a$ shows the diurnal variation in $\mathrm{PM}_{2.5}$ and $\mathrm{PM}_{10}$ from 27 May to 2 June 2014 obtained from the System for Air Quality Forecasting and Research (SAFAR), which records air quality in Delhi and the National Capital Region (NCR). In the present study, air quality data were retrieved from India Meteorological Department (IMD), Lodhi Road station. The values of $\mathrm{PM}_{10}$ and $\mathrm{PM}_{2.5}$ exceeded the severe category of air quality index and visibility reduced to around $500 \mathrm{~m}$ during the dust event. A sudden increase in the levels of $\mathrm{PM}_{2.5}$ and $\mathrm{PM}_{10}$ was observed at around 17:00 LST on 30 May. The concentration of $\mathrm{PM}_{10}$ on the dust day $\left(933 \mu \mathrm{g} \mathrm{m}^{-3}\right)$ was found to be approximately five times higher than that on the previous day $\left(189 \mu \mathrm{g} \mathrm{m}^{-3}\right)$ recorded at the same time (at 17:00 LST). The daily average $\mathrm{PM}_{10}$ value on the dust day $\left(514 \mu \mathrm{g} \mathrm{m}^{-3}\right)$ was almost thrice the $\mathrm{PM}_{10}$ value of the entire month $\left(182 \mu \mathrm{g} \mathrm{m}^{-3}\right)$.

However, the concentration of $\mathrm{PM}_{10}$ dropped drastically to $114 \mu \mathrm{g} \mathrm{m}^{-3}$ in the next $1 \mathrm{~h}(18: 00 \mathrm{LST})$. This is because the intense dust event was accompanied by a severe thunderstorm that caused heavy rainfall, and thus washing away the particulate matter (Figure $3 b$ ). Hourly average concentration of $\mathrm{PM}_{2.5}$ was found to be five times higher $\left(570 \mu \mathrm{g} \mathrm{m}^{-3}\right)$ during the dust episode as compared to the non-dust episode on the previous day $\left(115 \mu \mathrm{g} \mathrm{m}^{-3}\right)$ at 17:00 LST. Similar decline in $\mathrm{PM}_{2.5}$ levels was observed from 18:00 LST onwards due to heavy rainfall. The ratio of $\mathrm{PM}_{2.5}$ to $\mathrm{PM}_{10}$ was found to be 0.6 during May and June. It remained the same during the high PM episode as well. Therefore, it can be conferred that there was equal contribution from both fine-mode and coarsemode particles in this episode. In order to further study the contribution sources of ambient particulate matter, data on $\mathrm{NO}, \mathrm{NO}_{x}, \mathrm{O}_{3}$ and $\mathrm{CO}$ were also collected from the SAFAR system (Figure $3 c$ ). As evident from Figure $3 c$, there was no significant increment in the values of $\mathrm{O}_{3}$ and $\mathrm{NO}_{x}$ during the dust event. This indicates that the drastic increase in PM concentration was due to primary aerosols and not secondary aerosols. The primary aerosol sources could be either dust or combustion sources. Since the concentrations of $\mathrm{CO}$ and NO did not show any significant increment during the dust event, chances of emissions from combustion sources adding up to PM concentrations are feeble. Thus, trans-boundary transport 

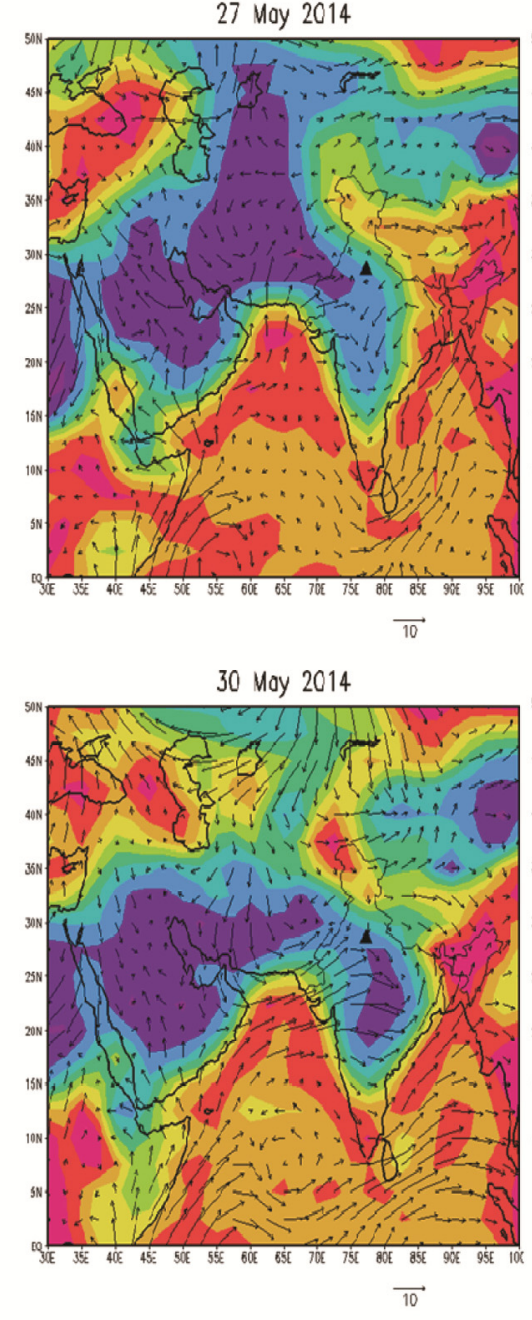

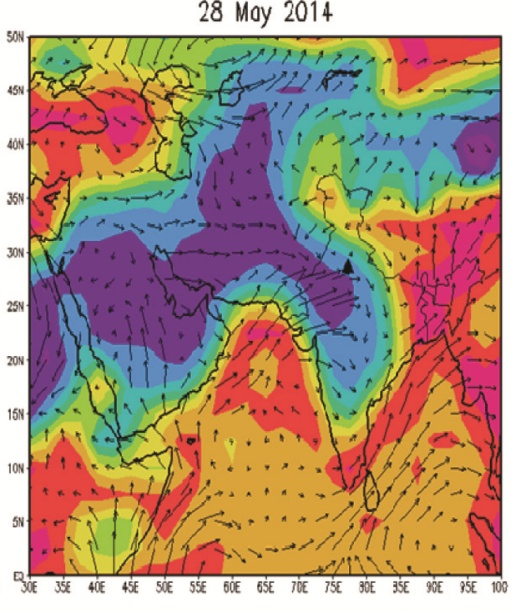

$\overrightarrow{12}$

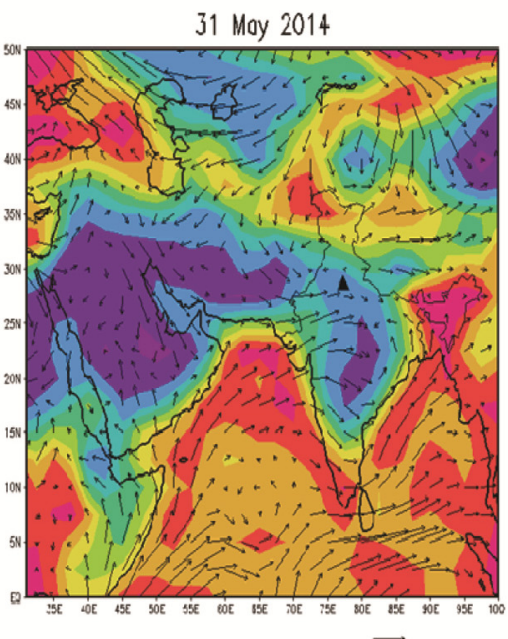

$\overrightarrow{13}$

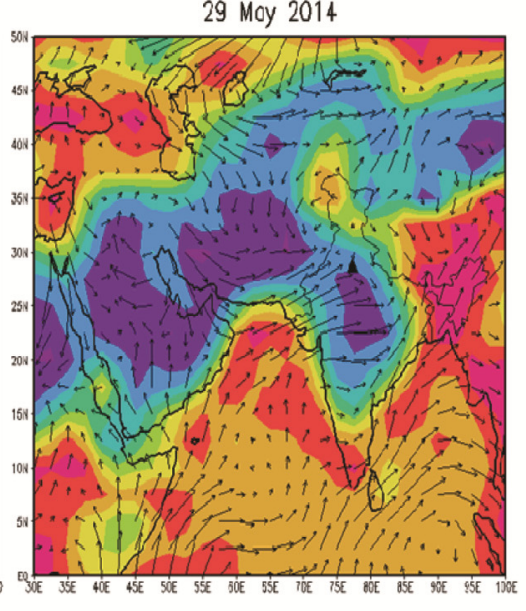

$\overrightarrow{10}$

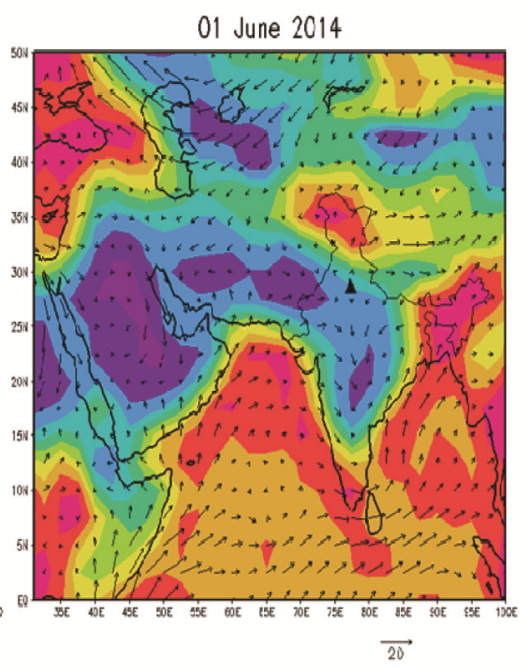

Figure 2. Wind pattern and wind speed $(\mathrm{m} / \mathrm{s})$ at $925 \mathrm{hPa}$ over Southwest Asia from 27 May to 1 June 2014 . Relative humidity $(\%)$ is shown in different colours.

of dust is considered the only possible source of contribution to this episode.

\section{Aerosol optical depth and Angstrom exponent}

Dust activities significantly influence the aerosol optical properties over the IGP. Dust aerosols interfere with the transmission of solar radiation by scattering, absorbing or redistributing shortwave solar radiation. As mentioned earlier, the sky radiometer enables estimation of aerosol optical properties ${ }^{13}$. AOD is a crucial parameter to measure the total columnar aerosol load in atmosphere. The spectral dependence of measured AOD is determined by $\mathrm{AE}$, which is also a good indicator of average aerosol particle size. Higher AE indicates the presence of smaller aerosol particles. The values of AE range from more than 2.0 for fine-mode particles near combustion sources to near zero for coarse-mode particles such as desert dust ${ }^{13}$. AE can be calculated from two or more wavelengths using a least squares fit method as

$$
\mathrm{AE}=-\ln \left(\tau_{\lambda 1} / \tau_{\lambda 2}\right) / \ln \left(\lambda_{2} / \lambda_{1}\right)
$$

where $\tau_{\lambda 1}$ and $\tau_{\lambda 2}$ are the optical thickness values at wavelengths $\lambda_{1}$ and $\lambda_{2}$ respectively.

The impact of dust episode is evident from the high AOD values and low AE values (Figure $4 a$ and $b$ ). Earlier studies have also revealed a reversal in AOD and AE during the periods of intense dust storms over IGP $^{10-12,26}$. The daily mean AOD $(500 \mathrm{~nm})$ on 30 May $(1.456 \pm$ $0.158)$ was twofold higher than that on the preceding non-dust day $(0.779 \pm 0.119)$, indicating high aerosol loading in the atmosphere due to dust storm. A similar increase in standard deviation of AOD marks the larger 

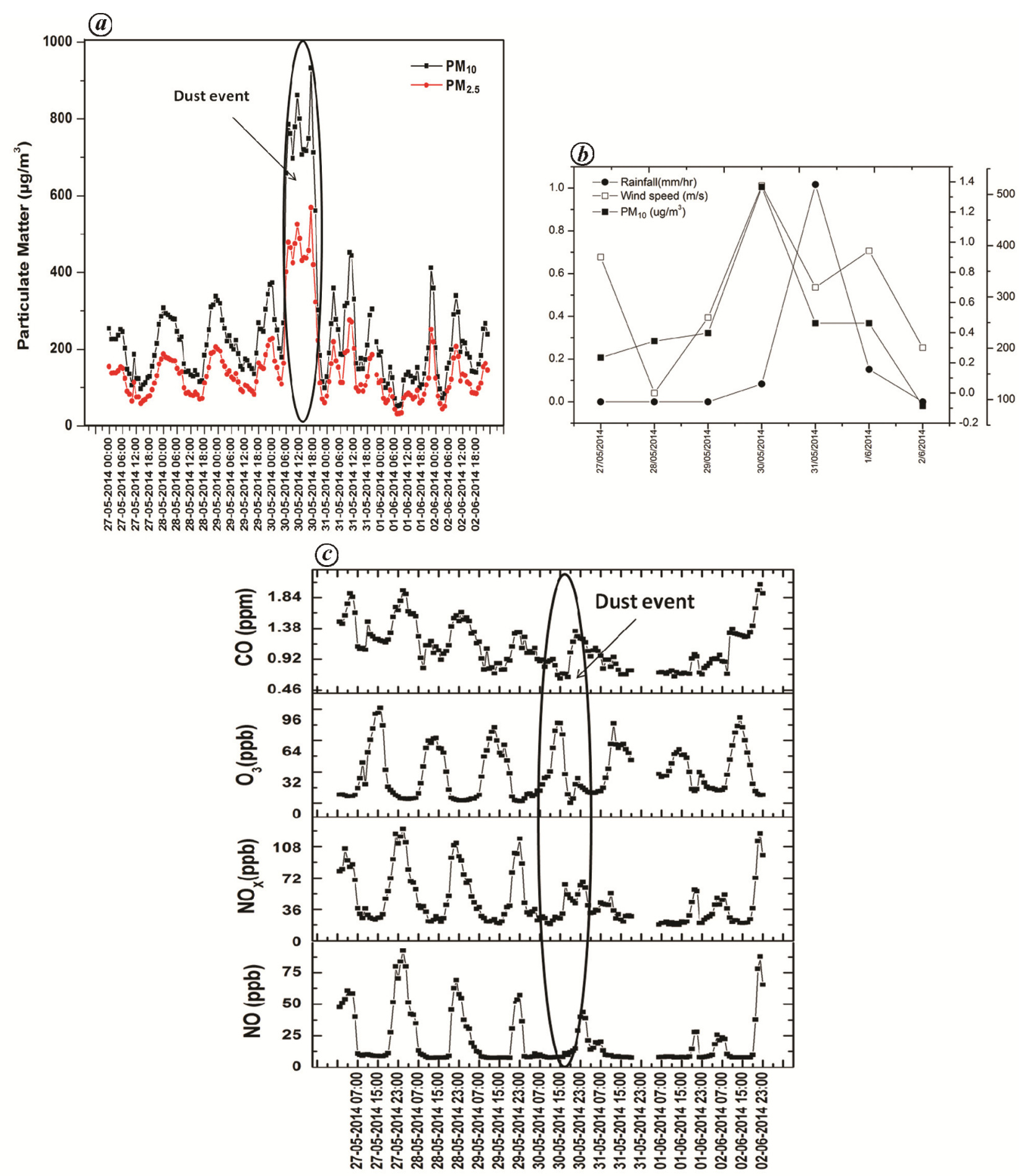

Figure 3. (a) Variation in $\mathrm{PM}_{10}$ and $\mathrm{PM}_{2.5}$, (b) rainfall, wind speed and $\mathrm{PM}_{10}$, and (c) $\mathrm{NO}, \mathrm{NO}_{x}, \mathrm{O}_{3}$ and $\mathrm{CO}$ at India Meteorological Department (IMD), Lodhi Road, New Delhi from 27 May to 2 June 2014.

variability in aerosol loading on the dust day. In general, the spectral variation in AOD depicts higher values at lower wavelengths, indicating presence of more finemode particles ${ }^{10,27}$. However, spectral variation of AOD shown in Figure $4 a$ depicts a slight deviation from the common wavelength dependency. As observed from the figure, there was $50-70 \%$ reduction in average daily AOD values from 340 to $1020 \mathrm{~nm}$ wavelength on the non-dust days. On the contrary, there was only $27 \%$ reduction on 30 May, showing a less steeper slope at higher wavelengths $(>675 \mathrm{~nm})$ during the dust episode. This can be attributed to the fact that interaction of incoming solar 

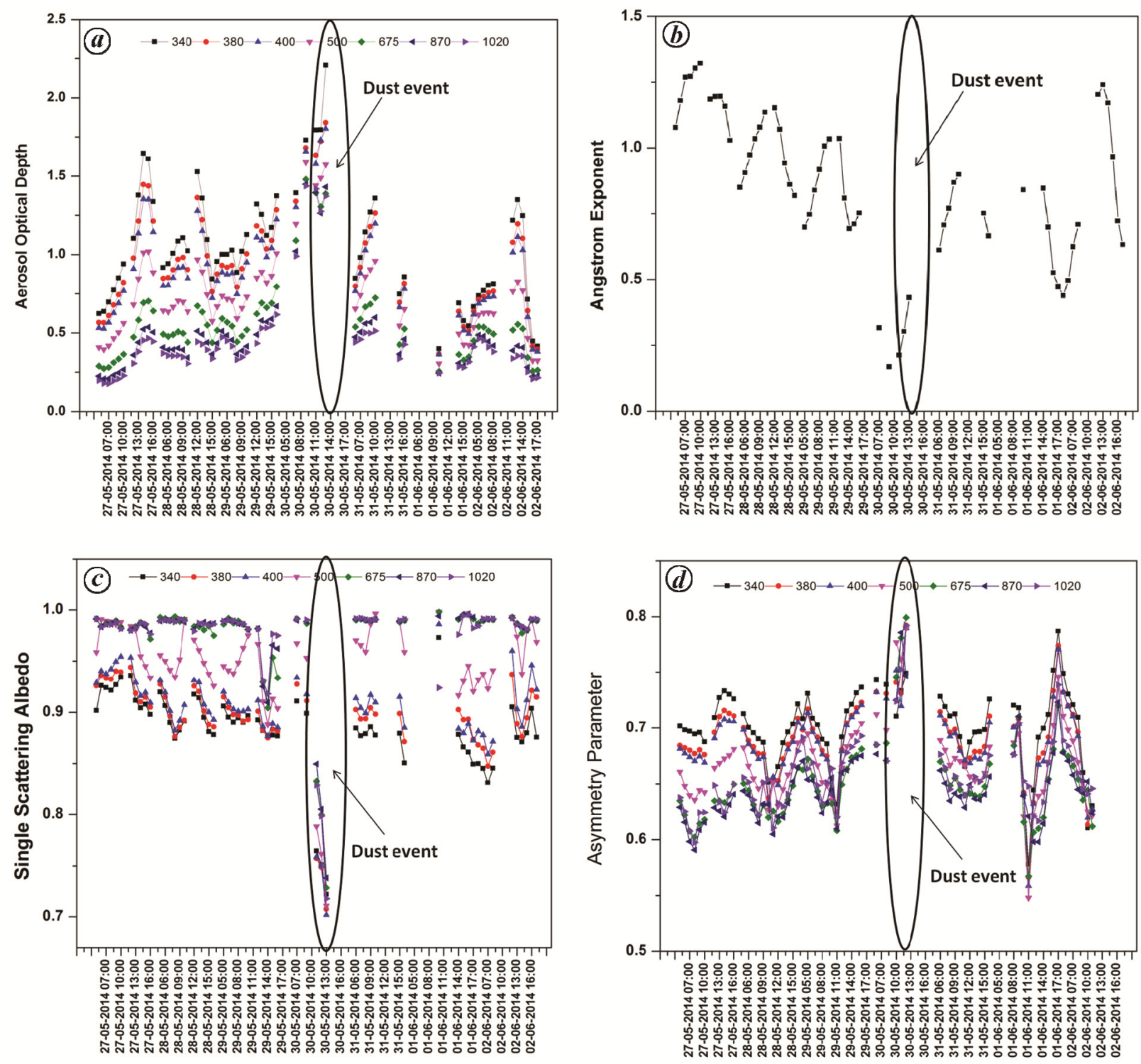

Figure 4. Diurnal variation in (a) aerosol optical depth (AOD), (b) Angström exponent (AE), (c) single scattering albedo (SSA) and (d) asymmetry parameter (ASY) from 27 May to 2 June 2014 at IMD, Lodhi Road, New Delhi.

radiation at higher wavelengths is influenced by dust aerosols of larger radii, resulting in lower wavelength dependency ${ }^{10}$.

The sharp decline in daily mean AE values from 0.8 on 29 May to 0.2 on 30 May indicates incidence of coarsemode desert dust particles in the atmosphere. On 30 May, it reduced to almost $50 \%$ of the average AE recorded during the study period. This reduction was due to dust particles causing extinction of incoming solar radiation, resulting in lower values of AE. The measurements were not available in the afternoon hours after 13:30 LST due to arrival of dust plume resulting in decline in direct beam irradiance. As the dust storm was accompanied by a thunderstorm, the heavy rainfall following the severe dust event helped settle down the airborne dust particles, resulting in a sudden decline in AOD and increase in AE on 31 May.

\section{Single-scattering albedo and assymetry parameter}

SSA associated with atmospheric aerosols is defined as a fraction of scattering in total extinction of solar radiation by aerosols ${ }^{11,13}$, mathematically represented as

$$
\omega=\frac{\alpha_{\mathrm{sca}}}{\sigma_{\mathrm{ext}}}=\frac{\sigma_{\mathrm{sca}}}{\sigma_{\mathrm{sca}}+\sigma_{\mathrm{abs}}},
$$

CURRENT SCIENCE, VOL. 118, NO. 5, 10 MARCH 2020 
where $\sigma_{\text {sca }}$ is the scattering coefficient and $\sigma_{\text {ext }}$ is the extinction coefficient which is the sum of $\sigma_{\text {sca }}$ and $\sigma_{\text {abs }}$ (absorbing coefficient).

SSA determines the absorbing or scattering characteristic of the aerosols. It is unity for purely non-absorbing particles and zero for strongly absorbing particles. Figure $4 c$ depicts the hourly average time series of SSA on dust and non-dust days. During the dust event in Delhi, the daily mean SSA at $500 \mathrm{~nm}$ suddenly reduced from 0.936 on 29 May to 0.836 on 30 May. This clearly indicates abundance of absorbing particles in the atmosphere. According to Dey et $a l .^{10}$, the light impinging on dust particles usually gets scattered. However, in this study the reduction in SSA values shows that dust particles are coated with other pollutants which have light absorbing properties. Thus, the light scattering and absorbing nature of dust significantly depends on the composition and chemical characteristics of the species coated on them. Delhi has abundant sources of absorbing aerosols like vehicular emissions, biomass burning and industrial units in the surrounding regions. The smoke generated from biomass burning is considered as absorbing aerosol constituting mostly high black carbon concentration ${ }^{28}$. A similar study by Kim et al. ${ }^{29}$ showed that SSA values for dust storms over East Asia decreased with higher wavelengths. This was interpreted as a result of mixing with anthropogenic aerosols comprising mainly organic aerosols and soot from biomass burning and fossil-fuel combustion. According to Moorthy et al. ${ }^{18}$ dust is found to be more absorbing over the Thar Desert compared to the Saharan dust. Further during pre-monsoon season, biomass burning activities like crop-residue burning are observed in the areas around Delhi, especially in the agricultural fields of Haryana, Punjab and Uttar Pradesh ${ }^{30-32}$. Also, as evident from Figure 1 wind trajectories reaching the station pass through the regions of biomass burning, which raises the surface concentration of black carbon during this season ${ }^{31}$. Therefore, wind carries the already absorbing form of dust from the Thar Desert, biomassburning aerosols from the northwest and anthropogenic aerosols within Delhi that enhance the absorptive property of dust.

Further in this study, the absorption Angström exponent (AAE) was analysed, which describes the wavelength variation of aerosol absorption and is used for aerosol characterization studies ${ }^{33}$. It is obtained from the spectral variations in absorption aerosol optical depth (AAOD) by computing the negative slope of its natural $\operatorname{logarithm}^{12}$. AAOD is computed as ${ }^{12,33}$

$$
\operatorname{AAOD}(\lambda)=[1-\operatorname{SSA}(\lambda)] \times \operatorname{AOD}(\lambda),
$$

where $\lambda$ is the wavelength. Generally, AAE values close to 1 indicate occurrence of black carbon-rich aerosols, whereas mineral dust and organic aerosols have higher AAE values. Considering the present study location and duration, the estimated daily mean AAE values (340$1020 \mathrm{~nm}$ ) lie in the range $0.1-0.7$. It was observed that AAE reduced to 0.1 on the dust day compared to nondust days. This suggests that dust particles were coated with aerosols which were more absorbing in nature (especially black carbon). Figure 5 shows the variation in daily average values of black carbon and AAE during the study period. The measurement of black carbon mass concentration was carried out using a seven-channel Aethalometer (Model AE-31, Magee Scientific Company, USA) at IMD, New Delhi. Higher black carbon concentration was noted with corresponding lower AAE value $(\sim 0.1)$ on the dust day (30 May). Large AAE values have been reported for Sahara dust aerosols ${ }^{33}$. However, dust in the present study is transported from the Middle East and the Great Indian Desert, coated with black carbon over the IGP, resulting in lower SSA and AAE values. This is in agreement with a study by Srivastava et $a l .^{34}$, where AAE values for Delhi were found to be less than 1 . Higher values of AAE (1-2) were reported by Alam et $a l .^{35}$ at Lahore, indicating dominance of carbonaceous aerosols emitted from power plants and industries in the region. Due to the presence of a complex mixture of natural and anthropogenic aerosols, AAE values differ at different regions ${ }^{33,36}$.

During the seven-day study period, SSA showed strong spectral variation as it increased with wavelength (Figure $6)$. This is due to the presence of more coarse-mode particles at higher wavelengths. However, the spectra showed steeper rise (higher slope value) between 400 and $675 \mathrm{~nm}$ wavelengths on non-dust days compared to the dust day (30 May). Several studies suggest that dust aerosols are more absorbing at shorter wavelengths due to the presence of silica and iron oxide ${ }^{10,28}$. In the present study, however, the opposite is observed, which can be due to mixing of the already absorbing type of dust with a large

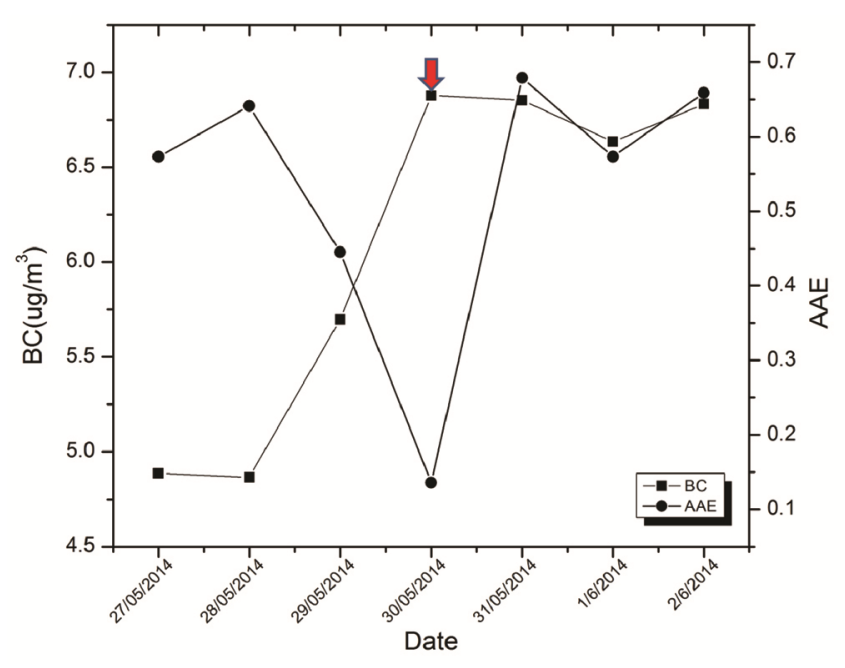

Figure 5. Daily variation in black carbon and absorption Angström exponent during the study period. Arrow indicates dust event. 


\section{RESEARCH ARTICLES}

pool of anthropogenic light-absorbing aerosols over the IGP during their transport ${ }^{20,37}$. Li et al. ${ }^{38}$ further confirmed that SSA of dust aerosols can be low if coarsemode particles dominate fine-mode particles. This also depends on the size distribution of aerosols, in which at least one component is light-absorbing.

A slight fall in the peak of SSA value at $1020 \mathrm{~nm}$ on the dust day further justifies the absorbing nature of dust. The steepness of SSA slope on the dust day was found to be in accordance with the AOD spectrum. Also, SSA at $500 \mathrm{~nm}$ increased from 0.836 on 30 May (dust-influenced day) to 0.975 on 31 May, because of the heavy rainfall that followed the dust storm which swept away coarse dust particles from the atmosphere.

On the contrary, ASY, which represents the angular distribution of light scattering due to aerosols ${ }^{13}$, showed an opposite trend with the daily mean value increasing from 0.65 on non-dust days to 0.75 on the dust day (Figure $4 d$ ). It is basically the cosine-weighted average of scattering angle and is given by the equation

$$
\operatorname{ASY}(\lambda)=\frac{1}{2} \int_{0}^{\pi} \cos (\theta) P(\lambda, \theta) \sin (\theta) \mathrm{d} \theta
$$

where $\theta$ represents the angle between the incident and scattered radiation, and $P(\lambda, \theta)$ is the phase function ${ }^{39}$. The average values ranged between 0.63 and 0.70 on the normal days before and after the dust storm. The values were relatively higher on the dust-influenced day. The ASY value ideally lies in the range -1.0 (for completely backscattering light with $\theta=180^{\circ}$ ) to +1.0 (for entirely forward-scattering light with $\left.\theta=0^{\circ}\right)^{34}$. The value of ASY depends on different aerosol types, usually with an average value approximating to 0.72 at $500 \mathrm{~nm}$ wavelength $^{34,40}$. Figure $4 d$ also depicts spectral variation in

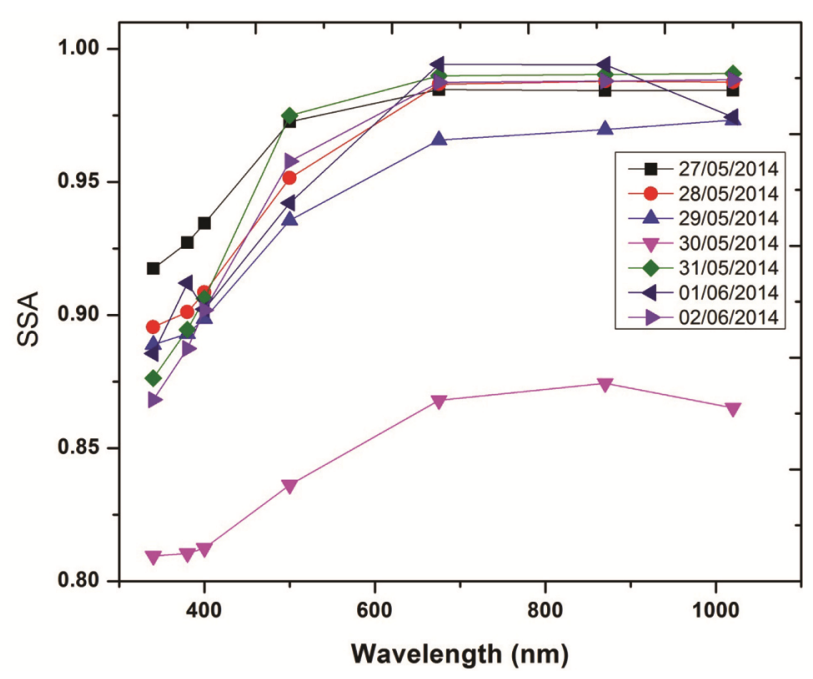

Figure 6. Spectral variation in SSA during the study period.
ASY from 340 to $1020 \mathrm{~nm}$ wavelength. Overall, ASY was observed to have decreased with wavelength in the visible range and slightly increased in the near-infrared region $(870 \mathrm{~nm}$ onwards), suggesting the presence of mixed type of aerosols, including fine- and coarse-mode particles $^{41}$. In the visible range, there was a constant decline over the non-dust days. This decrease with wavelength was weaker on the dust-influenced day, corresponding to dominance of coarse-mode particles causing strong forward scattering ${ }^{42}$. ASY depends on composition and size of aerosols, and is a fundamental parameter contributing to the radiative forcing. Andrews et al. ${ }^{43}$ showed $19 \%$ reduction in forcing at TOA and $13 \%$ at the surface with $10 \%$ decrease in ASY values.

\section{Volume-size distribution of aerosols}

The radiative properties of aerosols not only depend on aerosol concentration and chemical composition, but also on their size distribution. Thus, computation of aerosol volume size distribution is critical to characterize the fine- and coarse-mode particles in the atmosphere. It was computed from the direct Sun and diffuse sky radiance data obtained from the sky radiometer instrument using Skyrad.pack radiative transfer model (v.4.2) with 20 radius size bins in the range of $0.01-16 \mu \mathrm{m}$. The volume size distribution has a bimodal structure ${ }^{44}$, which can be characterized by the sum of two lognormal distributions as

$$
\frac{\mathrm{d} V}{d \ln r}=\frac{V_{0}}{\sigma(2 \pi)} \exp \left(-\frac{\ln \left[r / r_{\mathrm{m}}\right]^{2}}{2 \sigma^{2}}\right),
$$

where $\mathrm{d} V / d \ln r$ represents the volume size distribution, $V_{0}$ the volume of particles across the atmospheric column, $r$ the radius, $r_{\mathrm{m}}$ the modal radius and $\sigma$ is the standard deviation of the natural logarithm of the radii ${ }^{44}$. Generally, aerosol size is classified into three volumetric mod$\mathrm{es}^{45}$. Figure 7 illustrates variation in volume size distribution of aerosols during the study period. Two peaks are evident from the figure, one between 0.05 and $0.25 \mu \mathrm{m}$ and the other between 0.25 and $16 \mu \mathrm{m}$, indicating bimodal size distribution, representing the fine and coarse modes respectively. The volume concentration of coarse-mode particles $(0.25-16 \mu \mathrm{m})$ showed the highest peak on 30 May, i.e. dust day compared to the other days. On this day, the maximum volume size distribution occurred at the radii of 0.118 and $5.289 \mu \mathrm{m}$ with corresponding volume concentration peaks at 0.036 and 0.875 respectively. Generally, the aerosols generated from vehicular emissions and biomass burning are dominated by fine accumulation-mode aerosols. Whereas dust usually composed of desert soil material is dominated by coarse particles $^{11}$. The same was observed in Figure 7, which 
Table 1. Daily average values of volume size distribution parameters over Delhi during the study period

\begin{tabular}{lcccccl}
\hline Date & $R_{\mathrm{f}}$ & $V_{\mathrm{f}}$ & $\sigma_{\mathrm{f}}$ & $R_{\mathrm{c}}$ & $V_{\mathrm{c}}$ & $\sigma_{\mathrm{c}}$ \\
\hline 27 May 2014 & 0.118 & 0.153 & 0.029 & 3.617 & 0.381 & 0.082 \\
28 May 2014 & 0.055 & 0.304 & 0.025 & 5.289 & 0.463 & 0.0921 \\
29 May 2014 & 0.055 & 0.285 & 0.022 & 5.289 & 0.615 & 0.122 \\
30 May 2014 & 0.081 & 0.084 & 0.019 & 11.31 & 1.81 & 0.384 \\
31 May 2014 & 0.055 & 0.171 & 0.017 & 11.31 & 0.848 & 0.087 \\
1 June 2014 & 0.055 & 0.245 & 0.022 & 16.54 & 0.89 & 0.444 \\
2 June 2014 & 0.055 & 0.363 & 0.028 & 5.289 & 0.389 & 0.079 \\
\hline
\end{tabular}

$R$, Effective radius; $V$, Volume concentration; $\sigma$, Geometric standard deviation; subscripts f and c represent fine and coarse mode particles respectively.

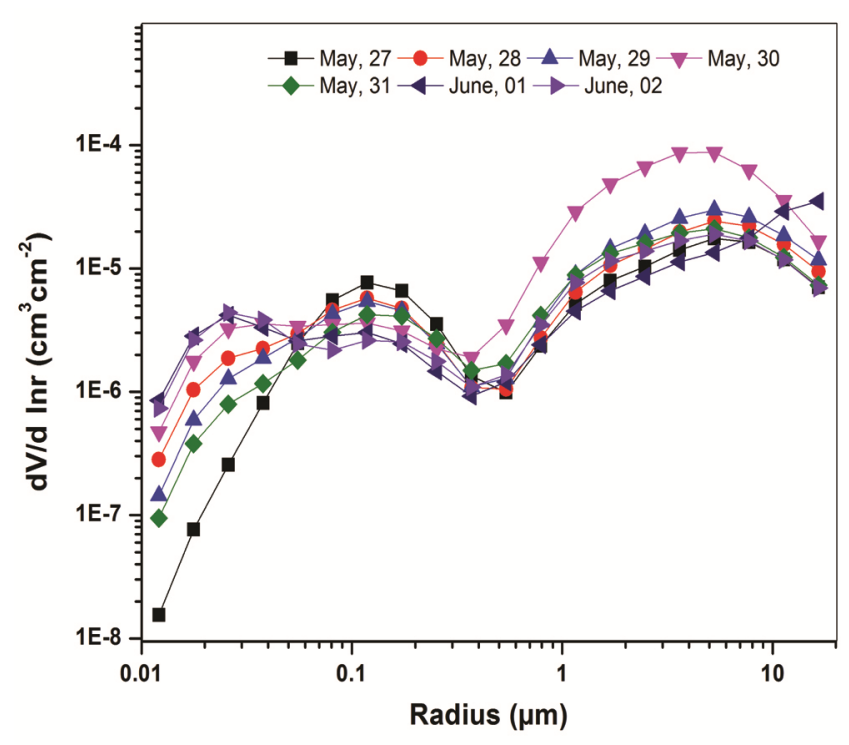

Figure 7. Volume size distribution of aerosols during the dust period at the study location.

showed a flat peak in the fine-mode range and a significantly heightened peak in the coarse-mode range of radii on the dust day. Indeed, the coarse-mode volume size distribution showed two to threefold increase on the dustinfluenced day compared to non-dust days. After the dust event declined, the volume size distribution of fine-mode particles with radii less than 0.1 was observed to increase. Table 1 gives the observed average daily values of volume size parameters during the study period. In this table, the daily average volume size distribution $(\mathrm{d} V / \mathrm{d} \ln R)$ for fine and coarse-mode particles is represented by $V_{\mathrm{f}}$ and $V_{\mathrm{c}}$ respectively, with the corresponding effective radius $R_{\mathrm{f}}$ and $R_{\mathrm{c}}$, and geometric standard deviation $\sigma_{\mathrm{f}}$ and $\sigma_{\mathrm{c}}$.

\section{Aerosol radiative forcing and heating rate}

ARF is defined as the difference in the net fluxes at TOA or the surface, with and without aerosols ${ }^{19}$. It is represented as

$$
\Delta F=F_{\text {aer }}-F_{\text {clean }},
$$

where $F_{\text {aer }}$ and $F_{\text {clean }}$ are net total solar flux (shortwave and longwave) at TOA or surface, with and without aerosols respectively. Attenuation of shortwave radiation and redistribution of longwave terrestrial radiation by aerosols produce direct radiative forcing. Dust also plays an important role in impacting the radiative heating by scattering, absorbing and re-radiating the solar radiation. The negative value of ARF indicates cooling of the Earthatmosphere system due to higher backscattering by aerosols, while positive value implies warming of the atmosphere. The direct aerosol radiative forcing (DARF) was computed in the shortwave spectral range $(0.3-4.0 \mu \mathrm{m})$ in the clean (without aerosols) and perturbed (with aerosols) atmospheric conditions at TOA and surface using the Santa Barbara Discrete-ordinate Atmospheric Radiative Transfer (SBDART) model ${ }^{46}$. The model utilizes AOD, SSA and ASY as input parameters derived from the sky radiometer at $0.4,0.5,0.675,0.87$ and $1.02 \mu \mathrm{m}$ wavelengths. MODIS-derived precipitable water content and TOMS-derived total column ozone for the study period were also utilized as inputs to the model. The other essential input parameters included were solar geometry, a model atmosphere (tropical for this study) and surface albedo. The surface albedo (at $500 \mathrm{~nm}$ ) was obtained from the Ozone Monitoring Instrument (OMI) aboard Aura satellite (version 3 reflectivity data).

ARF was calculated at hourly intervals over a 24-h period at TOA and the surface. Figure 8 shows the estimated daily average values of ARF at the surface, atmosphere and TOA. Shortwave ARF values at the surface, TOA and atmosphere on the dust day were noted as -82 , 10 and $92 \mathrm{~W} / \mathrm{m}^{2}$ respectively. These values were higher compared to the non-dust days because of higher aerosol loading in the atmosphere with AOD (500 nm) as 1.456 . It was observed in the study that TOA ARF on the dust day was positive in contrast to the negative values on the other days of measurement. This can be related to lower SSA values on this day, which resulted in increased absorption leading to a slight heating effect at TOA. Pandithurai et al. ${ }^{11}$ also determined radiative forcing values over Delhi during the dust-laden season of March to June 2006, and reported a tremendous increase in shortwave radiative forcing at TOA. A significant decline in temperature during the dust event could be justified by 
Table 2. Radiative forcing efficiency and corresponding heating rate/day over Delhi

\begin{tabular}{|c|c|c|c|c|}
\hline \multirow[b]{2}{*}{ Date } & \multicolumn{3}{|c|}{ Radiative forcing efficiency $\left(\mathrm{W} \mathrm{m}^{-2}\right.$ per unit $\left.\mathrm{AOD}_{500}\right)$} & \multirow[b]{2}{*}{ Heating rate $(\mathrm{K} /$ day $)$} \\
\hline & Surface & Top of the atmosphere & Atmosphere & \\
\hline 27 May 2014 & -35.113 & -28.544 & 19.734 & 1.156 \\
\hline 28 May 2014 & -44.780 & -23.560 & 21.220 & 1.157 \\
\hline 29 May 2014 & -58.871 & -11.917 & 46.954 & 1.157 \\
\hline 30 May 2014 & -56.878 & 6.909 & 63.788 & 1.433 \\
\hline 31 May 2014 & -59.957 & -9.534 & 50.422 & 1.147 \\
\hline 1 June 2014 & -61.768 & -17.157 & 44.610 & 1.157 \\
\hline 2 June 2014 & -71.325 & -4.007 & 67.318 & 1.158 \\
\hline
\end{tabular}

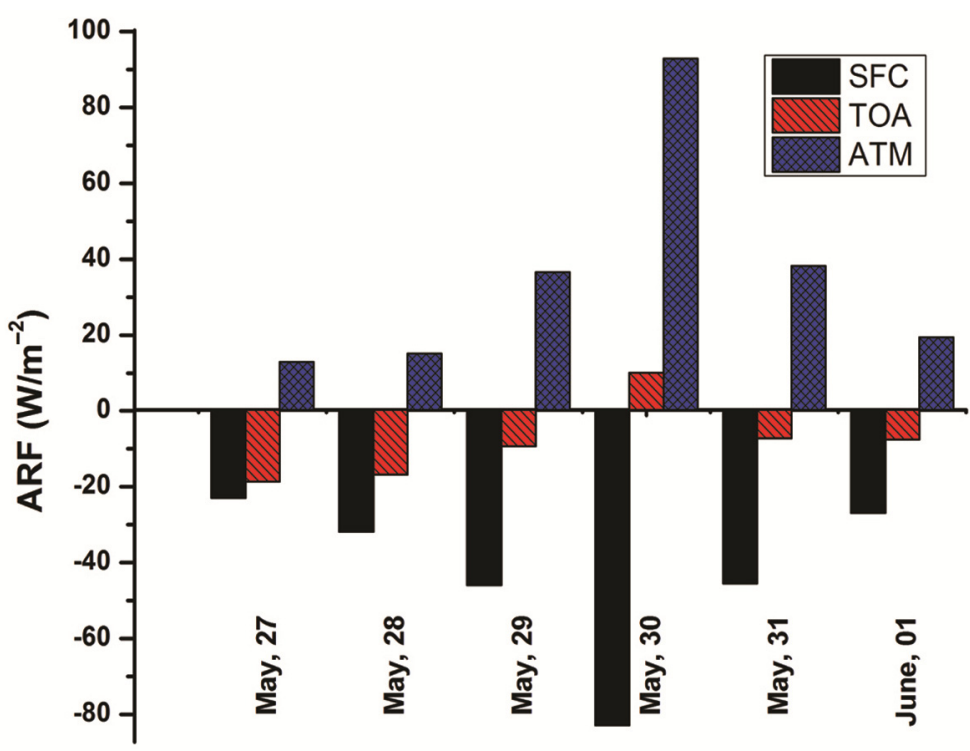

Figure 8. Aerosol radiative forcing (ARF) values for the study period at Delhi.

subsequent high negative radiative forcing at the surface.

The net positive radiative forcing gets transformed into heat. In order to observe the heat impact of dust storm in the lower atmosphere, the average heating rate due to aerosols was computed. This is defined as the rate of change of temperature $(\delta T / \delta t)$ due to radiative heating or cooling in a layer and expressed as ${ }^{47}$

$$
\frac{\delta T}{\delta t}=\frac{g}{C_{\mathrm{p}}} \frac{\Delta F_{\mathrm{atm}}}{\Delta P},
$$

where $\delta T / \delta t$ represents heating rate $\left(\mathrm{K} \mathrm{day}^{-1}\right), g$ the acceleration due to gravity, $C_{\mathrm{p}}$ the specific heat capacity of air at constant pressure, $\Delta F_{\text {atm }}$ the radiative forcing in atmosphere and $\Delta P$ is the atmospheric pressure between the top and bottom boundaries of each layer.

During the observational period, daily average of heating rates due to aerosols in the lower atmosphere from the surface to $500 \mathrm{~m}$ was calculated. Table 2 shows the results for atmospheric heating. The aerosol-induced heating rate during the study period varied from 0.156 to $1.433 \mathrm{~K} /$ day, with the highest heating on the dust day (30 May), as the atmospheric absorption of incoming solar radiation during dust activity translated into atmospheric heating.

Another significant parameter considered in the study was radiative forcing efficiency which represents the forcing potential of atmospheric aerosols. Table 2 also shows the values of forcing efficiency during the observation period. Due to the intense dust storm on 30 May, radiative forcing efficiency was relatively higher than on the non-dust days. In the study by Pandithurai et al. ${ }^{11}$, the surface forcing efficiency was reported to be higher during April-June over Delhi due to higher surface albedo values and lower SSA.

\section{Variation in precipitable water vapour content}

Measurement of PWV or column water vapour in the atmosphere is useful in evaluating the Earth's radiation budget. In the present study, PWV was retrieved from the 

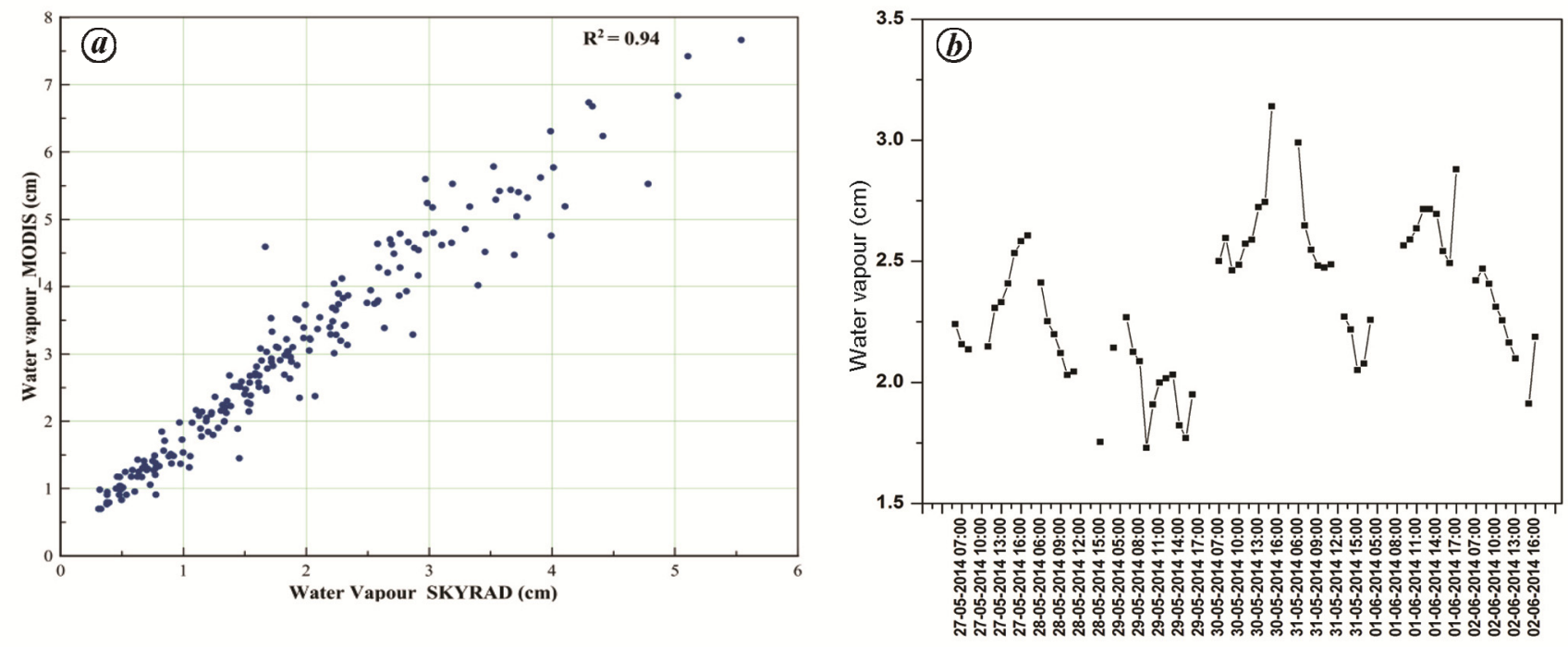

Figure 9. $\boldsymbol{a}$, Scatter plot of sky radiometer and MODIS precipitable water vapour (PWV). $\boldsymbol{b}$, Diurnal variation of PWV during the study period.

sky radiometer (POM-02), using the $940 \mathrm{~nm}$ channel. The method of retrieval is given in Estell'es et $a l^{23}$, using the ESR.pack developed by the European Skynet Radiometers network (ESR network). The daily columnar water vapour values thus retrieved from the above step were compared with the daily MODIS Terra (MOD08_D3) Level-3 global grid product of nearinfrared water vapour with clear column (NIR CC) available at $1^{\circ}$ spatial resolution (https://giovanni.gsfc.nasa. gov/). The scatter plot of daily average sky radiometer PWV and MODIS-PWV shows good agreement with correlation coefficient $(R)$ of about 0.94 (Figure $9 a$ ). The linear regression equation for the study region can be expressed in the form of $\mathrm{PWV}_{\text {MODIS }}=m * \mathrm{PWV}_{\text {SKYNET }}+\mathrm{c}$. A slope of more than unity indicates overestimation of MODIS PWV with respect to SKYNET retrieval.

During pre-monsoon season, enhancement of water vapour in the atmosphere is associated with dust activities $^{20}$. Jin et al. ${ }^{14}$ noted that changes in atmospheric circulations caused by dust activities can influence water vapour transport. Additionally, anthropogenic aerosols increase the precipitable water during dust events over northern India. According to Kim et al..$^{29}$ increased water vapour in the dust layer affects the radiative characteristics of the latter. In a study by Prasad et al. ${ }^{20}$ column water vapour was enhanced during dust storms in the summer season over the IGP. A pronounced increase in correlation between AOD and water vapour was observed over IGP due to the influence of dust events in the premonsoon season. Therefore, it is essential to study the variation in PWV during the dust episode. Figure $9 b$ shows the diurnal time series of columnar water vapour during the observation period. As evident from the figure, PWV content increased drastically during the dust storm hours $(>3 \mathrm{~cm})$. As the dust storm is a strong phenomenon, it could cause advection of ground-surface moisture leading to the possible increase in PWV content ${ }^{48}$. Since data were available only during the sunshine hours, the actual value of PWV immediately after the dust event could not be found. However, it remained around this level on the following day and started to decrease in the afternoon hours. This water vapour variability proves useful in understanding the occurrence of heavy rainfall immediately after the dust storm.

\section{Conclusion}

The long-range transport of dust was facilitated by strong winds resulting in dust emission from the Thar Desert, further extending to the northwestern parts of India. This study emphasizes on the impact of heavy dust activity on optical properties of atmospheric aerosols over the mega city of Delhi. Extremely low visibility up to $500 \mathrm{~m}$ was observed during the dust event in Delhi. The study revealed that ground-based measurement of the average daily AOD at $500 \mathrm{~nm}$ reached 1.456 at Delhi, while AE dropped to 0.287 on 30 May 2014. Low daily mean SSA at $500 \mathrm{~nm}$ was recorded as 0.85 on the dust day, indicating predominance of absorbing type of aerosols. An unusually high peak in $\mathrm{PM}_{10}$ concentration $\left(>933 \mu \mathrm{g} \mathrm{m}^{-3}\right)$ was observed during dust storm hours at Delhi on 30 May. The concentration of coarse-mode particles was observed to be higher on May 30 than the other days under study. The estimated daily shortwave ARF at the surface was -80.4 and $-45.5 \mathrm{Wm}^{-2}$ for 30 May and 31 May 2014 respectively, indicating a significant reduction in the radiative flux at the surface level. The net ARF resulted in cooling at the surface due to attenuation of incoming solar radiation by the dust layer. 
1. Hansen, J., Sato, M. and Ruedy, R., Radiative forcing and climate response. J. Geophys. Res., 1997, 102(D6), 6831-6864.

2. Ramanathan, V., Crutzen, Kiehl, J. T. and Rosenfeld, D., Aerosols, climate, and the hydrologic cycle. Science, 2001, 294, 2119 2124.

3. Miller, R. L., Tegen, I. and Perlwitz, J., Surface radiative forcing by soil dust aerosols and the hydrologic cycle. J. Geophys. Res., 2004, 109, D04203; doi:10.1029/2003JD004085.

4. Tegen, I., Werner, M., Harrison, S. P. and Kohfeld, K. E., Relative importance of climate and land use in determining present and future global soil dust emission. Geophys. Res. Lett., 2004, 31, L05105; doi:10.1029/2003GL019216.

5. Lau, K. M., Kim, M. K. and Kim, K. M., Asian summer monsoon anomalies induced by aerosol direct forcing: the role of the Tibetan Plateau. Climate Dyn., 2006, 26(7-8), 855-864; https://doi.org/10.1007/s00382-006-0114-z.

6. Charlson, R. J. and Heintzenberg, J., Aerosol Forcing of Climate, John Wiley, Chichester, UK, 1995.

7. Sharma, D., Singh, D. and Kaskaoutis, D. G., Impact of two intense dust storms on aerosol characteristics and radiative forcing over Patiala, northwestern India. Adv. Meteorol., 2012, 956814; https://doi.org/10.1155/2012/956814.

8. Mahowald, N., Albani, S., Kok, J. F., Engelstaeder, S., Scanza, R., Ward, D. S. and Flanner, M. G., The size distribution of desert dust aerosols and its impact on the Earth system. Aeolian Res., 2014, 15, 53-71.

9. Hsu, N. C., Tsay, S. C., King, M. and Herman, J., Aerosol properties over bright-reflecting source regions. IEEE Trans Geosci. Remote Sensing, 2004, 42, 557-569; https://doi.org/10.1109/ TGRS.2004.824067.

10. Dey, S., Tripathi, S. N., Singh, R. P. and Holben, B. N., Influence of dust storms on the aerosol optical properties over the IndoGangetic basin. J. Geophys. Res., 2004, 109, D20211; http:// dx.doi.org/10.1029/2004JD004924.

11. Pandithurai, G., Dipu, S., Dani, K. K., Tiwari, S., Bisht, D. S., Devara, P. C. S. and Pinker, R. T., Aerosol radiative forcing during dust events over New Delhi, India. J. Geophys. Res., 2008, 113, D13209; https://doi.org/10.1029/2008JD009804.

12. Srivastava, A. K., Soni, V. K., Singh, S., Kanawade, V. P., Singh, N., Tiwari, S. and Attri, S. D., An early South Asian dust storm during March 2012 and its impacts on Indian Himalayan foothills: a case study. Sci. Total Environ., 2014, 493, 526-534.

13. Taneja, K., Attri, S. D., Ahmad, S., Ahmad, K., Soni, V. K., Mor, V. and Dhankhar, R., Analysis of diurnal and seasonal variations in aerosol optical properties over a mega city and adjacent urban area in India. Mausam, 2017, 68(4), 673-688.

14. Jin, Q., Yang, Z. L. and Wei, J., Seasonal responses of Indian summer monsoon to dust aerosols in the Middle East, India, and China. J. Climate, 2016, 29, 6329-6349.

15. Alpert, P., Kishcha, P., Shtivelman, A., Krichak, S. O. and Joseph, J. H., Vertical distribution of Saharan dust based on 2.5-year model predictions. Atmos. Res., 2004, 70(2), 109-130.

16. Tanré, D. et al., Measurement and modeling of the Saharan dust radiative impact: overview of the Saharan Dust Experiment (SHADE). J. Geophys. Res., 2003, 108(D18), D8574.

17. Srivastava, M. K. et al., Aerosol optical properties over Delhi and Manora Peak during a rare dust event in early April 2005. Int. J. Remote Sensing, 2011, 32(23), 7939-7954.

18. Moorthy, K. K., Babu, S. S., Satheesh, S. K., Srinivasan, J. and Dutt, C. B. S., Dust absorption over the 'Great Indian Desert' using ground-based and satellite remote sensing. J. Geophys. Res., 2007, 112, D09206; https://doi.org/10.1029/2006JD007690.

19. Taneja, K., Soni, V. K., Attri, S. D., Peshin, S. K., Mor, V. and Sateesh, M., Seasonal asymmetry of aerosol optical and radiative properties over New Delhi, India using ground-based observations, In Global Sustainability Transitions: Impacts and Innova- tions (ed. Mishra, G. C.), Excellent Publishing House, New Delhi, 2014, pp. 124-130.

20. Prasad, A. K., Singh, R. P. and Holben, B. N., Changes in aerosol parameters during major dust storm events (2001-2005) over the Indo-Gangetic plains using AERONET and MODIS data. J. Geophys. Res., 2007, 112, D09208; https://doi.org/doi:10.1029/ 2006JD007778.

21. Rashki, A. et al., Spatio-temporal variability of dust aerosols over the Sistan region in Iran based on satellite observations. Nat. Hazards, 2014, 71, 563; https://doi.org/10.1007/s11069-013-0927$\underline{0}$.

22. Nakajima, T., Tonna, G., Rao, R., Kaufman, Y. and Holben, B., Use of sky brightness measurements from ground for remote sensing of particulate polydispersions. Appl. Opt., 1996, 35, 2672 2686.

23. Estell'es, V., Campanelli, M., Smyth, T. J., Utrillas, M. P. and Mart'inez-Lozano, J. A., Evaluation of the new ESR network software for the retrieval of direct sun products from CIMEL CE318 and PREDE POM01 sun-sky radiometers. Atmos. Chem. Phys., 2012, 12, 11619-11630; https://doi.org/10.5194/acp-1211619-2012.

24. Shaw, G. E., Error analysis of multi-wavelength sunphotometry. Appl. Geophys., 1976, 114, 1-14.

25. Tanaka, M., Nakajima, T. and Shiobara, M., Calibration of a sunphotometer by simultaneous measurements of direct-solar and circumsolar radiations. Appl. Opt., 1986, 25, 1170-1176.

26. Singh, S., Nath, S., Kohli, R. and Singh, R., Aerosols over Delhi during pre-monsoon months: characteristics and effects on surface radiation forcing. Geophys. Res. Lett., 2005, 32, L13808; http://dx.doi.org/10.1029/2005GL023062.

27. Eck, T. F. et al., Wavelength dependence of the optical depth of biomass burning, urban, and desert dust aerosols. J. Geophys. Res., 1999, 104, 0148-0227; https://doi.org/10.1029/1999JD900923.

28. Dubovik, O. et al., Variability of absorption and optical properties of key aerosol types observed in worldwide locations. J. Atmos. Sci., 2002, 59, 590-608.

29. Kim, D. H., Sohn, B. J., Nakajima, T., Takamura, T., Takemura, T., Choi, B. C. and Yoon, S. C., Aerosol optical properties over East Asia determined from ground-based sky radiation measurements. J. Geophys. Res., 2004, 109, D02209; doi:10.1029/ 2003JD003387.

30. Venkataraman, C. et al., Emissions from open biomass burning in India: integrating the inventory approach with high-resolution Moderate Resolution Imaging Spectroradiometer (MODIS) active fire and land cover data. Global Biogeochem. Cycles, 2006, 20, GB2013; doi:10.1029/2005GB002547

31. Beegum, S. N. et al., Spatial distribution of aerosol black carbon over India during pre-monsoon season. Atmos. Environ., 2009, 43, 1071-1078.

32. Devi, J. J., Tripathi, S. N., Gupta, T., Singh, B. N., Gopalakrishnan, V. and Dey, S., Observation-based 3-D view of aerosol radiative properties over Indian Continental Tropical Convergence Zone: implications to regional climate. Tellus B, 2011, 63(5), 971989; doi:10.1111/j.1600-0889.2011.00580.x

33. Russell, P. B. et al., Absorption Angstrom exponent in AERONET and related data as an indicator of aerosol composition. Atmos. Chem. Phys., 2010, 10, 1155-1169; http://dx.doi.org/10.5194/acp10-1155-2010.

34. Srivastava, A. K., Soni, V. K., Singh, S., Kanawade, V. P., Singh, N., Tiwari, S. and Attri, S. D., An early South Asian dust storm during March 2012 and its impacts on Indian Himalayan foothills: a case study. Sci. Total Environ., 2014, 493, 526-534.

35. Alam, K., Shaheen, K., Blaschke, T., Chishtie, F., Khan, H. U. and Haq, B. S., Classification of aerosols in an urban environment on the basis of optical measurements. Aerosol Air Qual. Res., 2016, 16, 2535-2549. 
36. Tiwari, S., Srivastava, A. K. and Singh, A. K., Heterogeneity in pre-monsoon aerosol characteristics over the Indo-Gangetic Basin. Atmos. Environ., 2013, 77, 738-747.

37. Khatri, P., Takamura, T., Shimizu, A. and Sugimoto, N., Observation of low single scattering albedo of aerosols in the downwind of the East Asian desert and urban areas during the inflow of dust aerosols. J. Geophys. Res. Atmos., 2014, 119, 787-802; doi:10.1002/2013JD019961.

38. Li, J., Carlson, B. E. and Lacis, A. A., Using single-scattering albedo spectral curvature to characterize East Asian aerosol mixtures. J. Geophys. Res. Atmos., 2015, 120, 2037-2052; doi:10.1002/2014JD022433.

39. Alam, K., Trautmann, T., Blaschke, T. and Subhand, F., Changes in aerosol optical properties due to dust storms in the Middle East and Southwest Asia. Remote Sensing Environ., 2014, 143, 216 227.

40. D’Almeida, G. A., Koepke, P. and Shettle, E. P., Atmospheric Aerosols: Global Climatology and Radiative Characteristics, A Deepak Publishing Co, Hampton, Virginia, USA, 1991.

41. Kumar, S., Singh, A. and Singh, A. K., Impact of 'Holi' festival on aerosol optical properties in Indo-Gangetic Plain. Int. J. Adv. Earth Sci., 2015, 4(1), 19-28.

42. Carraca, K., Hatzianastassiou, M. B., Matsoukas, C., Gkikas, A. and Papadimas, C. D., The regime of aerosol asymmetry parameter over Europe, the Mediterranean and the Middle East based on MODIS satellite data: evaluation against surface AERONET measurements. Atmos. Chem. Phys., 2015, 15, 13113-13132; https:// doi.org/10.5194/acp-15-13113-2015.

43. Andrews, E. et al., Comparison of methods for deriving aerosol asymmetry parameter. J. Geophys. Res., 2006, 111, D05S04; doi:10.1029/2004JD005734.
44. Dubovik, O. et al., Accuracy assessments of aerosol optical properties retrieved from Aerosol Robotic Network (AERONET) Sun and sky radiance measurements. J. Geophys. Res., 2000, 105, 9791-9806.

45. Whitby, K. T., The physical characteristics of sulfur aerosols. Atmos. Environ., 1978, 12(1-3), 135-159.

46. Ricchiazzi, P., Yang, S., Gautier, C. and Sowle, D., SBDART: research and teaching tool for plane-parellel radiative transfer in the Earth's atmosphere. Bull. Am. Meteorol. Soc., 1998, 79, $2101-$ 2114; https://doi.org/10.1175/1520-0477[1998]079<2101:SARATS $>$ 2.0. $\mathrm{CO} ; 2$.

47. Liou, K. N., An Introduction to Atmospheric Radiation, Elsevier, New York, USA, 2002.

48. Bhattacharjee, P. S., Prasad, A. K., Kafatos, M. and. Singh, R. P., Influence of a dust storm on carbon monoxide and water vapor over the Indo-Gangetic Plains. J. Geophys. Res., 2007, 112, D18203; doi:10.1029/2007JD008469.

ACKNOWLEDGEMENTS. We thank the Director General of Meteorology and Head, Environment Monitoring and Research Centre, India Meteorological Department, New Delhi for support and providing the necessary facilities and data to carry out this work. The use of MODIS dust images, Google Earth and HYSPLIT model of NOAA-ARL for back-trajectories is also acknowledged.

Received 28 February 2019; revised accepted 20 November 2019

doi: $10.18520 /$ cs/v118/i5/737-749 